\title{
Tédio na leitura de Beckett
}

Olga Kempinska

UFF

\section{Resumo}

Ao deslocar a questão da monstruosidade do domínio da temática para o domínio da estética voltada para a relação de fruição, este artigo debruça-se sobre o tédio enquanto uma componente do efeito da leitura. Descrito por Baudelaire como um "monstro delicado", o tédio, de fato, revela um forte potencial de tolher a configuração da forma. Frequentemente comparado à névoa, à poeira e à lama, fenômenos muito diferentes da tradicional hibridação formal associada à noção de monstruosidade, o tédio remete à informidade. Ele se deixa experimentar na leitura de narrativas de Beckett por meio de um ritmo que não culmina, impedindo a formação de representações, e suscitando uma reação ambivalente de repulsa e de atração.

Palavras-chave: Tédio; Monstruosidade; Ritmo; Samuel Beckett; Estética.

\section{Résumé}

En déplaçant la question de la monstruosité du domaine de la thématique vers celui de l'esthétique concernée par la relation entre le lecteur et l'œuvre, l'article se penche sur l'ennui en tant que composante de l'effet. Décrit par Baudelaire comme un " monstre délicat", l'ennui révèle de fait un fort potentiel d'empêcher la configuration de la forme. Fréquemment comparé à la brume, à la poussière et à la boue, phénomènes distincts de l'hybridation formelle traditionnellement associée à la notion de monstruosité, l'ennui relève de l'informité. Il se manifeste pendant la lecture des textes de Beckett à travers d'un rythme qui ne culmine pas, en empêchant la formation de représentations et en suscitant une réaction ambivalente de répulsion et d'attraction.

Mots-clés: Ennui; Monstruosité; Rythme; Samuel Beckett; Esthétique . 
1. GOMBROWICZ, Witold. Driennik 1953-1958, 1997, p. 153.

2. DALLE PEZZE, Barbara, e SALZANI, Carlo. "The Delicate Monster: Modernity and Boredom", 2009, p. 7.

3. (...). Em meio às hienas, às serpentes, aos chacais, / Aos símios, escorpiões, abutres e panteras, / Aos monstros ululantes e às viscosas feras, / No lodaçal de nossos vícios imortais, // Um há mais feio, mais iníquo, mais imundo! / Sem grandes gestos ou sequer lançar um grito, / Da Terra, por prazer, faria um só detrito / E num bocejo imenso engoliria o mundo; // É o Tédio! (...). BAUDELAIRE, Charles. As flores do mal, 2015, p. 97.
Mas a chuva a pregava no chão, a amassava com a grama e a terra numa espécie de pasta lamacenta, não uma pasta lamacenta, uma espécie de pasta lamacenta.

Samuel Beckett

"Um dia há de saber-se por que, no nosso século, tantos grandes artistas escreveram tantas obras ilegíveis", notou com seu característico atrevimento o escritor emigrante Witold Gombrowicz, para confessar ainda em seguida: "Com uma verdadeira admiração, com um sincero reconhecimento tive que interromper muitas leituras que por demais me entediavam"1. Entre autores mencionados, sem pudor, como aqueles que suscitam excessivo enfado, Gombrowicz - que, como veremos, é, de fato, um dos importantes exponentes do tédio -, menciona, por exemplo, Kafka. Ainda que não as cite, as narrativas de Beckett, sem dúvida, também poderiam constar na provocativa lista gombrowicziana de livros que caem das mãos. Na leitura de Beckett, mesmo aquela muito atenta, algo parece relutar em configurar-se, algo não toma forma, insistindo em demorar-se numa monstruosidade amorfa, tal uma neblina cinzenta, uma poeira ou uma lama, que é, aliás, uma das imagens mais recorrentes na poética beckettiana. Comparável a um amálgama sem articulação, o tédio nada tem a ver com os monstros confeccionados da hibridação animal, vegetal e humana. Ao contrário daquela exorbitância de formas, na experiência do tédio trata-se, antes, da impressão do contato com uma estranha substância, quase inexistente e, contudo, capaz de dissolver as formas mais horrendas. Lendo as narrativas de Beckett, tive, de fato, a impressão de algo que se obstinava em arrastar-se, não se completando, permanecendo vago e informe, trazendo consigo uma estranha lentidão - uma lentidão, por assim dizer, cada vez mais intensa - acompanhada de uma específica sensação de estagnação e frustração.

Vale a pena perguntar-se então por que Baudelaire, que tanto investigou uma das formas do tédio moderno, o spleen, utilizou em seu endereçamento ao leitor das Flores do mal, poema no qual Barbara Dalle Pezze e Carlo Salzani veem um verdadeiro "manifesto do tédio", justamente a expressão "monstro delicado" . De que "delicadeza" - suavidade, brandura, sutileza - pode tratar-se no caso do tédio? Capaz de engolir o mundo em um bocejo, o monstro delicado, quase imperceptível, ao contrário do impacto visual dos monstros horripilantes, revela seu potencial de tudo banalizar e nivelar - se não aniquilar - até os piores males e pecados. Mas donde viria toda essa força que, 
segundo Baudelaire, de longe supera em periculosidade os monstros mais hediondos? Para procurar a resposta a essa pergunta, talvez valha a pena investigar a experiência do tédio como uma componente da relação de fruição, deslocando, dessa maneira, a questão da monstruosidade do domínio da temática para o domínio da estética. Ainda que tenha crescido recentemente o número de considerações aprofundadas acerca do tédio na história social da cultura, na estética da recepção prevalecem sobretudo suas apreensões negativas, aquelas que persistem em considerá-lo como acidental e indesejável. Geralmente, o tédio - se é que surge como questionamento - é rapidamente relegado a fazer parte de um vago conjunto de inaptidões do leitor, relacionando-se obscuramente com um repertório cultural insuficiente ou com uma atenção faltosa. Por outro lado, uma vez que desde a afirmação, em 1931, dos lugares vazios como imprescindíveis articuladores da relação estética na fenomenologia da leitura de Roman Ingarden ${ }^{4}$, a teoria da recepção tem cada vez mais acolhido diversas formas da negatividade, investigando seu genuíno potencial estético, a experiência do tédio, quem sabe, também mereça uma análise menos simplória e unilateral.

É interessante notar ainda que Walter Benjamin, em 1933, ao debruçar-se sobre as mudanças das formas narrativas, e ao lançar sobre a experiência do tédio um olhar bastante saudoso, a tenha associado à lentidão - tão bem expressa pela palavra alemã Langeweile -, e descrito enquanto perdida no contexto da intensa aceleração rítmica da vida moderna. Apesar de desconsiderar sua tensão específica, responsável, como veremos, por sua ambivalência - talvez, mais sensível nas formas de tédio experimentadas em meio à vida urbana e à indústria cultural -, Benjamin não deixou, contudo, de apontar para um interessante potencial estético do tédio, tornando-o propício à recepção daquilo que as narrativas contêm "em camadas muito profundas" 5 , ou seja, enquanto não dito e latente. E se, para Goya, o sonho da razão produz monstros, para Benjamin, "o tédio é o pássaro de sonho que choca os ovos da experiência".

\section{O tédio e a negatividade}

Na esteira do pessimismo de Schopenhauer, o próprio Beckett, no ensaio juvenil sobre Proust, de 1931, que pode ser lido como um esboço de sua "teoria estética", enxerga na experiência do tédio a característica mais relevante e mais elementar da existência humana:
4. Cf. INGARDEN, Roman.

A obra de arte literária, 1973.

5. BENJAMIN, Walter. Magia e Técnica, Arte e Politica, 2010, p. 204.

6. Ibidem. p. 204.

7. POTHAST, Ulrich. Die eigentlich metaphysische Tätigkeit: über Schopenhauers Ästhetik und ibre Anwendung durch Samuel Beckett, 1989, p. 13. 
8. BECKETT, Samuel. Proust, 1986, p. 14.

9. A complexidade semântica do tédio traduz-se em suas diferentes expressões linguísticas: ennui, Langeweile, nuda, boredom, entre outros; talvez, apesar das tentativas de se captar as características gerais do tédio enquanto uma experiência tipicamente moderna e pósmoderna, não seja de todo vão levar em conta sua diversidade, tal como se costuma fazer no caso da melancolia, à qual correspondem vocábulos e realidades culturais irredutíveis: "acedia", "desengaño", "spleen", "Stimmung", "saudade", entre outros (Cf. LAMBOTTE, Marie-Claude. "Mélancolie", 2004, p. 758-765).

10. SVENDSEN, Lars. Filosofia do tédio, 2006, p. 20.

\section{BECKETT, Samuel. Malone} morre, 2014, p. 32.

12. Ibidem, p. 40.

13. Ibidem, p. 66.

14. Ibidem, p. 67.

15. Ibidem, p. 69.
Os períodos de transição que separam adaptações consecutivas (já que nenhum expediente macabro de transubstanciação poderá transformar as mortalhas em fraldas) representam as zonas de risco na vida do indivíduo, precárias, perigosas e férteis, quando por um instante o tédio de viver é substituído pelo sofrimento de ser. ${ }^{8}$

$\mathrm{Na}$ visão beckettiana da existência o tédio surge como o dado básico, como a experiência que recobre o todo da existência, sendo interrompido apenas por momentos de sofrimento. No âmbito dessa visão da vida, no qual "viver" equivale ao "tédio de viver", torna-se também visível a distinção entre o tédio e a tradicional melancolia ${ }^{9}$. Ainda que tenha relações genealógicas com o rico campo semântico das expressões do desgosto de viver, no tédio moderno, com efeito, pouco sobra daquele tradicional encanto que abria caminho à associação da melancolia "com a sabedoria, a sensibilidade e a beleza"10. O tédio não parece ter vínculos fortes com o regime do excepcional - tradicionalmente, o do gênio melancólico -, mas, ao contrário, com o domínio do repetitivo, comum, cotidiano e corriqueiro.

Em Beckett, a experiência do tédio manifesta-se como tema sobretudo em Malone morre, texto cujo protagonista-narrador, nem mais conseguindo arrastar-se, conta-se histórias para passar o tempo que o separa da morte. Repetidas vezes Malone interrompe seu gesto de contar com a constatação de um tédio, inevitável, invencível e desalentador: "Que tédio. E chamo isso de jogar"11; "Me pergunto por que estou falando de tudo isso. Ah sim, é para me desentediar" "12; "Que tédio. E se passasse para a pedra? Não, seria a mesma coisa"13; "Tédio mortal"14; "Suave mari magno, sobretudo no desembarque. Que tédio. E eu que acreditava ter tudo tão bem arranjado. Se pudesse usar meu corpo me jogaria pela janela" ${ }^{15}$. É justamente em Malone morre - publicado entre Molloy e O inominável, portanto, enquanto texto intermediário na trilogia do esvaziamento da representação -, que o tédio se encontra transformado em uma das questões principais. Para além de surgir como tema, o tédio da narrativa impressionou-me também como efeito experimentado durante minha leitura: de linha em linha, de página em página algo dificilmente descritível parecia delongar-se, confundir-se, dar voltas, descumprindo expectativas, e levando à impressão de fazer-me esperar à toa. Esparsas e incertas gratificações de humor ambivalente acrescentavam à essa sensação de espera em vão uma estranha sensação de impregnar-me por uma substância levemente pegajosa, tal minério.

Ao procurar descrever melhor esse efeito como uma forma de negatividade experimentada durante o ato da leitura, li alguns estudos que situam Beckett no âmbito da literatura do absurdo e da crise da linguagem. Muitos pesquisadores traçam 
paralelos entre sua trilogia e o Novo Romance ${ }^{16}$, no qual a indeterminação cronotópica e psicológica, a repetitividade e o uso da focalização externa resultam em um excesso de observação, fazendo com que o leitor experimente uma saciedade específica da ubiquidade do "real". Paulo Leminski assinalou, no entanto, uma profunda divergência estética entre a proposta francesa e a beckettiana, ao notar que "o crispado desespero metafísico-apocalíptico de Beckett nada tem a ver com a neutra objetividade tecnocrática do nouveau roman, no qual a recalcada religiosidade protestante de Beckett nada tem a fazer" ${ }^{\prime 17}$.

De fato, em Beckett, o excesso parece ter a ver não com os detalhes dos objetos observados, mas com o próprio funcionamento das palavras. Deparei-me então com um ensaio de Olga Bernal, de 1969. A autora, uma sobrevivente de Auschwitz, relaciona a crise da representação em Beckett a uma solidão atroz, que não deixa de fazer eco à angústia pascalina - Vivian Mercier chega a sugerir que "se Pascal tivesse sido romancista, quem sabe, teria escrito um equivalente seiscentista de Malone morre"18 -, da qual os seres humanos procuram escapar por meio de diversas distrações e jogos, tais como, por exemplo, o divertimento que consiste em inventar e contar histórias. Além disso, para viver é também preciso inventar sua própria história, em um genuíno gesto de inventar-se. Mas “para brincar de 'histórias', é preciso ter "brinquedos"”, 19 ou seja, palavras. Bernal é uma das primeiras a observar a estrutura da brincadeira especificamente beckettiana, que parece ser feita com brinquedos estragados. Pois suas palavras dão a impressão de estabelecer referências e temas apenas para logo anulá-los perversamente. Os brinquedos, parece, não funcionam como deveriam.

Afinal, não seria possível brincar com brinquedos estragados? Brincadeira séria - um jogo cuja aposta é vida ou morte -, as narrativas de Molloy, de Malone e do Inominável abandonam a vontade de ganhar e abraçam a vontade de perder, fazendo da experiência do tédio um elemento constitutivo do efeito estético.

Segundo Wolfgang Iser, que explora a negatividade inerente à recusa do sentido na estética beckettiana nas páginas finais de seu Ato da leitura, os textos da trilogia expõem o leitor a uma considerável densidade de negações primárias. Responsáveis pela constituição da referencialidade, as negações primárias irremediavelmente afetam a construção das frases e a configuração do tema, fazendo com que o leitor se depare com uma grande dificuldade na formação das representações. A invencível sensação de que a leitura do texto beckettiano envolve um esforço empreendido (e renovado) à toa encontra, dessa maneira, uma explicação bastante convincente: "o leitor experimenta o constante cancelamento das significações do texto que ele criara e,
16. Cf. FRIEDMAN, J. Melvin. "Samuel Beckett and the Nouveau Roman", 1960, p. 22-36.

17. LEMINSKI, Paulo. "Beckett, o apocalipse e depois", 1986, p. 149 .

18. MERCIER, Vivian. Beckett/ Beckett. The classic study of a modern genius, 1977, p. 171.

19. BERNAL, Olga. Langage et fiction dans le roman de Beckett, 1969, p. 181. 
20. ISER, Wolfgang. O Ato da leitura, 1999, p. 187.

21. BECKETT, Samuel. O inominável, 2009, p. 29.

22. Ibidem, p. 39.

23. Idem. Malone Morre, 2014, p. 88.

24 Idem. O inominável, 2009, p. 39.

25 Idem. Molloy, 2014, p. 54.

26. LEMINSKI. "Beckett, o apocalipse e depois", 1986, p. 155. por causa dessa negação, é impelido a observar a natureza projetiva dessas significações atribuídas ao texto" ${ }^{20}$. O próprio narrador de $O$ inominável formula, aliás, um diagnóstico parecido ao comentar seu gesto de narrar enquanto "afirmações e negações invalidadas à medida que são expressas" 21 , como, por exemplo, na frase "Eu disse que aqui tudo se repete mais cedo ou mais tarde, não, ia dizê-lo, depois reconsiderei" ${ }^{22}$. Frequentemente, esse procedimento paradoxal explora os deslizes e os interstícios entre função referencial e metalinguística:

Em breve, quer dizer, daqui a dois ou três dias, para falar como quando me ensinaram os nomes dos dias e me surpreendi que fossem tão pouco numerosos, e agitava meus pequenos punhos gritando, Mais! Mais! e o significado dos mostradores, e o que é isso, dois ou três dias, no fim das contas, a mais ou a menos, uma piada. ${ }^{23}$

Outras vezes, ainda, é o próprio acúmulo da negatividade que acaba por desafiar a lógica e por confundir a fronteira entre negação e afirmação: "Eis aí um que não é como eu não saberei jamais não ser" 24 . Outras confusões surgem também na fronteira entre ficção e realidade: "Dizer é inventar. Falso como se espera. Você não inventa nada, acredita inventar, escapar, não faz mais que balbuciar sua lição, restos de um castigo, tarefa decorada e esquecida, a vida sem lágrimas, tal como você a cho$\mathrm{ra}^{25}$. Após a experiência da tradução de Malone morre, Leminski chegou a esboçar uma lista de interferências relativizadoras ou anuladoras, que "intoxicam" a linguagem beckettiana: "talvez", "quem sabe", "de certa maneira", "visto de um certo ângulo", "se bem me lembro", "se os meus olhos não me enganam", bem como adjetivos tais como "certo", "algum", "qualquer"26.

Ao negar o que acaba de ser afirmado, ao tomar expressões ao pé da letra, ao oscilar entre os níveis referencial e metalinguístico, a linguagem beckettiana atrapalha não apenas os voos da imaginação leitora, mas até mesmo a própria experiência da emergência do sentido. Em vez da constituição da representação, que culminaria a tensão relacionada ao esforço do percurso do texto, experimentamos o funcionamento - ou antes a disfunção - da própria linguagem. Nossa atenção alimenta-se com vacilantes lampejos de humor ambivalente que dificilmente provocam o riso (que constituiria uma culminação e, com isso, alguma solução da tensão psíquica). É como se tivéssemos em mãos um brinquedo quebrado - digamos, um carrinho sem uma roda -, que não serve muito bem para brincar de corrida, mas que não deixa de produzir um estranho fascínio devido a sua composição faltosa. Pois um brinquedo defeituoso frequentemente deixa à mostra seu mecanismo. A falta, a abertura e o desnudamento não podem senão exercer um efeito 
de atração, convidando-nos a prosseguir, a levar mais longe a desmontagem, mais um pouco, para ver o que tem dentro, para descobrir como o brinquedo é feito, como funciona. Ou como poderia funcionar. A exploração do mecanismo afasta-nos cada vez mais do movimento da própria brincadeira. Podemos então dizer que Beckett faz o leitor fazer com as palavras tudo aquilo que Baudelaire havia descrito como a vã exploração do brinquedo em busca de sua alma: "A criança vira e revira seu brinquedo, esfrega-o, agita, bate com ele na parede, joga no chão. De quando em quando, faz com que recomece seus movimentos mecânicos, às vezes em sentido inverso"27. Substituída pela exploração e pela desmontagem do mecanismo, a própria brincadeira não continua, não avança, não se conclui, e a experiência da leitura do texto beckettiano, ao invés de se dar como uma atividade de alimentar e de satisfazer a curiosidade por meio da constituição e da acumulação de sentido, assemelha-se, antes, a uma constante protelação. O próprio movimento da leitura em O Inominável até mesmo os parágrafos se tornam cada vez mais raros, dificultando a localização de pausas, fazendo com que o leitor mergulhe em um amálgama que preenche páginas e páginas -, arrasta-se de forma tenaz e indeterminada. Onde foi que eu parei? - Pergunta-se o leitor querendo prosseguir com a leitura: uma pergunta desesperançada, uma vez que a disposição gráfica do texto torna inevitável a perda de orientação (no meu exemplar de O Inominável, de segunda mão, há marcações com caneta nas margens...).

Dessa maneira, pode-se também ver no recurso à língua estrangeira, gesto fundador da poética de Beckett, uma prática solidária do gesto de estragar a brincadeira, substituindo-lhe a desmontagem dos brinquedos. O próprio bilinguismo da obra beckettiana revela-se, nesse sentido, inerente à elaboração de uma poética da afirmação da tradução enquanto "paradigma dos intercâmbios linguísticos" ${ }^{28}$. Falar torna-se, de fato, equivalente a traduzir - e, aos olhos de Beckett, somos todos péssimos tradutores de nós mesmos -, enquanto que assistir à encenação desse processo de má tradução na recepção do texto de Beckett tem na experiência do tédio sua componente necessária.

\section{O tédio e o ritmo}

É comum associar o tédio à repetitividade e à monotonia, poucas vezes, contudo, explica-se por que estas o produzem. Para investigar essa questão e para captar melhor a monstruosidade específica manifesta na relação estética com o texto
27. BAUDELAIRE, Charles.

"Morale du joujou", 1853, s/p.

28. ARROJO, Rosemary. Tradução, Desconstrução e

Psicanálise, p. 51. 
29. ABRAHAM, Nicolas. Rhythms. On the Work, Translation and Psychoanalysis, 1995, p. 21.

30. Ibidem, p. 23.

31. Ibidem, p. 75 .

32. SOKOLOWSKI, Robert. Introdução à fenomenologia, 2004, p. 147.

33. ABRAHAM. Rhythms, 1995 , p. 114. beckettiano procurei compreender a experiência do tédio enquanto uma experiência rítmica. Antes de tudo, tornou-se necessário explicar em que sentido a experiência rítmica enquanto tal deve ser pensada como relacionada à produção de uma forma e como intrinsicamente voltada para a culminação. Pois parece que, na experiência da leitura dos textos de Beckett, são justamente esses os elementos responsáveis pelo efeito do tédio.

É no trabalho de Nicolas Abraham, que procura descrever o alcance do ritmo na experiência estética, debruçando-se sobre sua natureza a partir do âmbito interdisciplinar da fenomenologia e da psicanálise, que a indagação acerca da expectativa de culminação rítmica encontra sua formulação convincente. "Em vez de falarmos da 'percepção do ritmo', seria melhor falarmos da 'ritmização da percepção"'29, nota Abraham, ressaltando a reciprocidade inerente à consciência rítmica, que se cria enquanto forma ao criar seu objeto. A ritmização da percepção é também acompanhada de uma experiência de desrealização, "pois a consciência ritmada é em certo sentido prisioneira do ritmo que implacavelmente leva a efeito a protensão daquilo que vem depois" ${ }^{30}$. Ao nos entregarmos ao ritmo em uma experiência sugestiva e envolvente, que beira encantamento, vemo-nos também mergulhados em uma tensão específica, inseparável da expectativa que "nada mais é do que o esboço de um momento futuro que tira sua motivação dos movimentos passados"31. Lançando mão da visão fenomenológica do tempo, segundo a qual a experiência do presente é inseparável da retenção do passado e da protensão do futuro, pois "o presente vivo, como o todo, é composto" "32, Abraham assinala que a experiência da articulação da temporalidade coincide com a expectativa de repetição.

Quanto à orientação da repetição rítmica para a culminação, esta encontra sua plena explicação apenas quando a visão fenomenológica da reciprocidade rítmica é enriquecida pela teoria psicanalítica da economia da repressão do desejo inconsciente. De fato, uma vez que a realização do desejo se vê constantemente frustrada, e que aquilo que se realiza é sempre "algo outro", diferente do desejado, "o presente não pode solidificar-se em uma satisfação definitiva; precisa, antes, deslizar implacavelmente na direção de um outro presente" ${ }^{33}$. Nesse sentido, a própria formação da subjetividade em sua relação com a repressão do desejo, ou seja, enquanto uma história de repressões, coincide com a criação de uma temporalidade marcada pela tensão. Assim, no processo da recepção do texto literário, as identificações simbólicas sucessivamente internalizadas pelo leitor veem-se diretamente envolvidas na dinâmica da repressão sendo, com isso, marcadas pelo caráter extratemporal do desejo. Em um certo sentido, o leitor realiza a identificação apenas para ultrapassá-la. Como explica Abraham, se na dinâmica afetiva da identificação os afetos possuem o caráter eminentemente 
prospectivo, é porque as identificações simbólicas são rapidamente transformadas em novos obstáculos da realização do desejo:

Qual é a base dessa necessidade tipicamente humana de manter vivo o desejo e de ludibriá-lo por meio de satisfações apenas simbólicas? A pergunta toca ao próprio motivo da criação do tempo. A resposta deve ser procurada no domínio no qual a psicanálise situou o problema desde o início: na imaturidade sexual da criança (...). Simplificando um pensamento complexo, pode-se dizer que o verdadeiro fundamento da criação do tempo remete ao inevitável conflito da imaturidade que propulsa o sujeito de um estágio de desenvolvimento a outro. Em cada estágio, uma forma de satisfação é reprimida em prol da outra, que se torna ao mesmo tempo nova e simbólica da precedente. Concomitantemente, novos obstáculos são internalizados através de identificações simbólicas. O escopo do ego vê-se progressivamente aumentado. ${ }^{34}$

No processo da leitura, a possibilidade de realização de uma identificação simbólica depende sobretudo da formação de representações. Ora, dado que na fruição do texto beckettiano a emergência da representação é constantemente atrapalhada pela densidade das negações primárias, a experiência da leitura depara-se com entraves justamente no que tange à experiência da culminação. De fato, sem a formação de representações, não há possibilidade de se realizar as identificações simbólicas, e, assim, nada se cumpre, nada culmina, e nada pode ser ultrapassado. Com isso, nada avança nem se desenvolve, ao contrário, algo parece desacelerar. O leitor continua sempre "na mesma", enxergando, eventualmente, na própria dificuldade de locomoção dos personagens beckettianos, que estão muito longe de ir em frente, questionando, antes, o "mistério de caminhar" 35 amarrados em uma cadeira, caindo de bicicleta, rolando escada abaixo, dando voltas, perdendo-se, rastejando, ou imobilizados, para citarmos alguns exemplos - uma metáfora de sua relação com o texto. E pior: à medida que se percorre as páginas, a sensação de ficar parado, de não conseguir avançar, é cada vez mais pungente, transformando-se em uma sensação de estar preso. Com isso, a experiência rítmica assemelha-se em Beckett à imobilização da tensão, à colocação da culminação em uma situação de constante deferimento, à interminável insatisfação, que produzem como seu efeito justamente o tédio.

\section{O tédio e a fruição}

À primeira vista, devido a sua relação com o deferimento da culminação, o tédio aparece sobretudo como uma experiência
34. Ibidem, p. 115-116.

35. Cf. STALLYBRASS, Peter. O casaco de Marx. Roupas, memória, dor, 2008. 
36. BARTHES, Roland. O prazer do texto, 2013, p. 33.

37. PHILIPS, James. "Beckett's Boredom", 2009, p. 110.

38. Ambas palavras provêm de " $n e d z i c$ ", que expressa a ideia de carência (Cf. BRÜCKNER, Aleksander. Stownik etymologiczny jesyka polskiego, 1929, p. 358-359).

39. GOMBROWICZ. Driennik 1953-1958, 1997, p. 89.

40. Ibidem, p. 147.

41. Ibidem, p. 477.

42. Ibidem, p. 478. negativa. No entanto, tal como a espera da morte que é o tema de Malone morre - a espera é um dos temas mais recorrentes de Beckett -, da mesma maneira a espera frustrada do leitor da narrativa beckettiana por algo que não chega a efeito não deixa de ser profundamente ambivalente. Nesse sentido, vários autores insistem, de fato, na ambivalência específica do tédio no qual o excesso (de tempo) se conjuga com a falta (de evento); a repulsa (da aflição) com a atração (do irresistível mergulho), enfim, o prazer com o desprazer. Em que sentido seria então possível enxergar na tensão que não se resolve e no ritmo que não culmina uma experiência esteticamente produtiva? Barthes, por exemplo, em sua teoria irreverente da fruição, chega a aproximar o tédio do gozo e a afirmar que "o enfado não está longe da fruição" 36 insistindo na complexidade da irresolução, própria ao tédio. James Philips, ao associar o tédio beckettiano à noção heideggeriana de ambiência, enxerga em meio a sua experiência traços da estrutura do prazer negativo, característico do sublime, constatando ainda: "Beckett curte o tédio" ${ }^{37}$.

A ambivalência específica do tédio parece remeter a sua situação instável entre carência e excesso. É justamente dessa maneira que a palavra "tédio" (nuda; em polonês), surge, por exemplo, nas páginas do diário de Gombrowicz. Em polonês a palavra compartilha sua etimologia com a palavra "náusea"38 e ambas se relacionam com a ideia de falta. Em Gombrowicz, o tédio surge inicialmente associado à carência, sendo sinônimo de expressões tais como "desinteressante", "desprovido de vida", "não divertido", "sem espírito de jogo". Assim, por exemplo, ao falar sobre as comissões, o escritor polonês associa o tédio à falta de interesse: "Mesmo que me mandassem uma delegação com música e flores, não participaria das comissões, que me dão um tédio mortal" ${ }^{39}$. Na descrição de esforço do seu próprio estilo, Gombrowicz traça uma equivalência entre o tédio e a falta de vida: "Consegui mostrar de modo, parece, não tedioso, mas divertido, ou seja, humano e vivo, como a forma se cria entre nós, como ela nos cria" ${ }^{40}$. Na famosa provocação "Contra os poetas", o tédio é descrito como o efeito dos poemas, remetendo ao excesso de repetição em sua forma: "E, no entanto, eu me coloco frente a vocês e afirmo que não gosto nem um pouco de poemas e que chego a ficar com eles entediado" ${ }^{41}$. "Por que não suporto aquele canto monótono, continuamente elevado, por que me fazem dormir o ritmo e a rima, por que a linguagem dos poetas parece-me a menos interessante de todas?"42. O excesso surge, aliás, na aproximação entre o tédio e a ideia de algo "demasiado sério". Mas o exemplo mais pungente da relação entre tédio e excesso surge em Gombrowicz no chocante exemplo da reação ao sofrimento de bilhões de seres humanos: "Repeti em voz alta 'me dá tédio o sofrimento 
nessas quantidades' e fiquei ouvindo o sentido dessas palavras, estranho, incrível mesmo, e tão meu (humano)" ${ }^{43}$. Notemos de passagem que os pesquisadores que procuram ver no tédio uma emoção adaptativa, comparam-no ao excesso análogo ao estado de saciedade alimentar e até mesmo ao "nojo suscitado por comidas tóxicas" ${ }^{\prime 4}$.

Um dos temas recorrentes do diário do escritor emigrante, elaborado a partir de 1953 - portanto, contemporâneo do existencialismo e de Malone morre, publicado em francês em 1953 e em inglês em 1956 -, o tédio analisado por Gombrowicz não se limita à apercepção negativa unilateral, tingindo-se frequentemente de outras nuances e tornando-se ambivalente. Ao refletir, por exemplo, sobre o sofrimento das moscas e do mundo animal, e sobre a relação do ser humano com a natureza, o escritor chega a experimentar uma certa vertigem do tédio e, dessa maneira, um de seus sinônimos, "não atraente", sofre uma significativa desestabilização, passando a oscilar entre repulsa e atração:

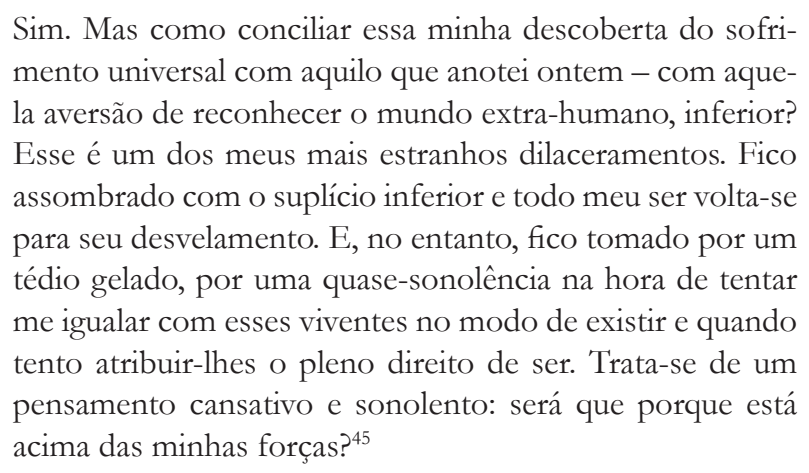

Envolto na dinâmica complexa de atração e repulsa, o tédio torna-se um lugar emocional e esteticamente instável, uma passagem aberta entre nojo e indiferença. Além disso, o tédio releva-se em Gombrowicz como marcado por um movimento de direção reversível. Com efeito, quando critica a seriedade excessiva da retórica, o escritor relaciona o tédio a uma contagiosa falta de espírito de jogo: "o mundo se tornou estupida e mortalmente sério e as nossas verdades, às quais recusamos o espírito de jogo, ficam entediadas e, vingando-se, passam também a entediar-nos" ${ }^{46}$. Experimentado como pegajoso, o tédio revela seu potencial de gerar o efeito de reciprocidade.

Uma vez que o tédio parece, de fato, intensificar a nossa tendência a "desnaturar" ou até a inverter "a relação sujeito-objeto" "47, a relação de fruição que o envolve como um de seus componentes dificilmente permite o controle da distância estética. Observemos como, no trecho de Malone morre, o abuso de uma expressão idiomática, "não custar nada", faz oscilar a atenção leitora entre a função referencial e a metalinguística, gerando
43. GOMBROWICZ, Witold. Driennik. 1959-1969, 1997, p. 184.

44. TOOHEY, Peter. Boredom. A lively history, 2011, p. 33.

45. GOMBROWICZ. Driennik 1953-1958, 1997, p. 372.

46. Ibidem, p. 116.

47. CATALUCCIO, Francesco

M. Gombrowicz filozof, 1991, p. 12. 
48. BECKETT. Malone morre, 2014, p. 103.

49. BAUDELAIRE. As flores do mal, 2015, p. 97.

50. SVENDSEN. Filosofia do tédio, 2006, p. 133.

51. WALSER, Robert. Absolutamente nada e outras bistórias, 2014, p. 45.

52. LA ROCHEFOUCAULD. Reflexões ou sentenças e máximas morais, 2014, p. 96. um certo efeito humorístico; como a afirmação e a contradição se confundem por meio da aparentemente inocente expressão "na pior das hipóteses", desestabilizando a formulação do tema; como, afinal, aquilo que deveria ser o objeto da representação - um abrigo -, por meio de um excesso de sua especificação, perdendo muito de sua verossimilhança, transforma-se em um lugar de confinamento:

Mas para passar agora a uma outra ordem de considerações, talvez seja lícito desejar a Macmann, porque desejar não custa nada, eventualmente uma paralisia generalizada poupando na pior das hipóteses os braços se isso é concebível, num lugar impermeável tanto quanto possível ao vento, à chuva, ao barulho, ao frio, às grandes ondas do calor como no século VII e à luz do dia, com um ou dois edredons úteis para tudo e uma alma caridosa, digamos, semanal, encarregada das maçãs cortadas e das sardinhas no azeite destinadas a adiar até os extremos limites do possível o prazo fatal, isso seria maravilhoso. ${ }^{48}$

No desequilíbrio característico do tédio, tudo aquilo que remetia à tradicional monstruosidade com sua insistência no disforme - àqueles "monstros ululantes"49 do poema de Bauldelaire -, é carcomido pelo amorfo. Com o tédio, praticamente invisível, a tradicional forma mal configurada atribuída ao regime do monstruoso vê-se ameaçada pela dissolução e, assim, a uma forma malfeita segue-se uma falta de forma, colocando em questão os limites da própria monstruosidade. Na leitura das narrativas de Beckett, ao experimentar o funcionamento da própria linguagem, o leitor experimenta também o próprio tempo enquanto algo que reluta em avançar. Surge então aquela específica "temporalização da temporalidade" ${ }^{50}$, anunciada no início do século XX por Robert Walser, que colocou em uma de suas breves narrativas a seguinte observação: "somente por tédio alguém dá ouvidos aos murmúrios da alma" ${ }^{51}$. Ao mesmo tempo, o potencial dissolvente do amorfo releva-se dotado de uma energia paradoxal. "O tédio extremo serve para nos desentediar" "52, constatou La Rochefoucauld, apontando para a complexidade da tensão específica do enfado e para sua iminente reversibilidade. E de fato, na leitura de Beckett, ao experimentar a estagnação rítmica relacionada ao constante cancelamento das significações do texto, o leitor se depara com a impossibilidade de realizar e, com isso, de ultrapassar suas identificações simbólicas. O estranho prazer estético parece remeter então à ambivalência do tédio enquanto excesso (de tempo) e falta (de sentido, produzido e ultrapassado). Pois na experiência da leitura das narrativas beckettianas algo nunca chega a termo, mas também, algo nunca se esgota. Solidário da temática da espera e da poética do monólogo interior relacionado à expressão do 
pensamento emergente "mais íntimo, o mais próximo do inconsciente, anterior a toda organização lógica" ${ }^{53}$, o tédio parece, de fato, avesso a qualquer conclusão.

Enquanto um excesso (de tempo) e uma falta (de evento), o tédio surge como uma pobreza paradoxal. Ou como uma riqueza paradoxal, se alguém preferir. Uma das perguntas que me faço, retornando aos textos de Beckett e lendo-os em um ritmo decrescente, levando um mês inteiro para ler aquele livro que da última vez li em uma semana, é se o tédio deve ser realmente combatido. Nesses nossos tempos que nada têm de novo, e que já se entediaram mil vezes de mentir sobre esse assunto, repetindo à saciedade aquelas prerrogativas mal digeridas da acumulação, no fundo das quais desde sempre ecoou o "cada vez mais" compulsivo do monstro voraz consumista, o tédio talvez seja a proposta estética. Ou, talvez, aquela velha pergunta pelo "como" também aqui seja a pergunta. Barthes parece já ter pensado nisso, quando escrevia: "Pode-se perguntar se há um modo falso e um verdadeiro de se entediar" 54 . Pode-se também procurar por formas rítmicas de uma sensibilidade capaz de fruir o próprio potencial amorfo do tédio. Beckett parece ter feito um quase convite nesse sentido, ao dizer "mesmo o caminho mais enfadonho tem todo um outro aspecto, todo um outro enfado, na volta que na ida, e vice-versa" ${ }^{\prime 5}$.

\section{Referências}

ABRAHAM, Nicolas. Rhythms. On the Work, Translation and Psychoanalysis. Trad. B. Thigpen e N. T. Rand. Stanford:

Stanford University Press, 1995.

ARROJO, Rosemary. Tradução, Desconstrução e Psicanálise. Rio de Janeiro: Imago, 1993.

BARTHES, Roland. O prazer do texto. Trad. J. Guinsburg. São Paulo: Perspectiva, 2013. O grão da voz. Trad. M. Laranjeira. São Paulo: Martins

Fontes, 2004.

BAUDELAIRE, Charles. "Morale du joujou". In. Le Monde Littéraire, 1853. Disponível em : http://www.bmlisieux.com/ litterature/baudelaire/moraljou.htm. Último acesso em 31.08.2016. As flores do mal. Trad. I. Junqueira. São Paulo: Nova Fronteira, 2015.
53. SALLENAVE, Danièle. "Em torno do 'monólogo interior': leitura de uma teoria", 1976 , p. 112.

54. BARTHES, Roland. O grão da voz, 2004, p. 16.

55. BECKET'T. O inominável, 2009 , p. 61. 
BECKETT, Samuel. Proust. Trad. A. R. Nestrovski. Porto Alegre: L\&PM, 1986.

_. Malone morre. Trad. A. H. Souza. São Paulo: Globo, 2014.

Molloy. Trad. Ana Helena Souza. São Paulo: Globo, 2014.

. O inominável. Trad. A. H. Souza. São Paulo: Globo, 2009.

BENJAMIN, Walter. Magia e Técnica, Arte e Politica. Trad. S. P. Rouanet. São Paulo: Ed. Brasiliense, 2010.

. Charles Baudelaire: um lírico no ange do capitalismo. Trad.

J. C. Martins Barbosa e H. Alves Baptista. Rio de Janeiro: Ed. Brasiliense, 1991.

BERNAL, Olga. Langage et fiction dans le roman de Beckett. Paris: Gallimard, 1969.

BRÜCKNER, Aleksander. Stownik etymologiczny jesyyka polskiego, Cracóvia: Krakowska Spółka Wydawnicza, 1929.

CATALUCCIO, Francesco M. (org.). Gombrowicz filozof. Cracóvia: Znak, 1991.

FRIEDMAN, J. Melvin. "Samuel Beckett and the Nouveau Roman”. In. Wisconsin Studies in Contemporary Literature, 1960.

GOMBROWICZ, Witold. Driennik 1953-1958. Cracóvia: Wydawnictwo Literackie, 1997.

. Driennik 1959-1969. Cracóvia: Wydawnictwo Literackie, 1997.

INGARDEN, Roman. A obra de arte literária. Trad. A. E. Beau et al. Lisboa: Calouste Gulbenkian, 1973.

ISER, Wolfgang. O Ato da leitura. Uma teoria do efeito estético. Vol. 2. Trad. J. Kretschmer. São Paulo: Editora 34, 1999.

LA ROCHEFOUCAULD. Reflexões on sentenças e máximas morais. Trad. R. Freire, d'Aguiar. Companhia das Letras, 2014.

LAMBOTTE, Marie-Claude. "Mélancolie". In: CASSIN, Barbara (org.) Vocabulaire européen des philosophies. Paris: Seuil\&Le Robert, 2004, p. 758-765.

LEMINSKI, Paulo. "Beckett, o apocalipse e depois”. In: BECKETT, Samuel. Malone morre. Trad. P. Leminski. São Paulo: Ed. Brasiliense, 1986, pp. 145-157. 
MERCIER, Vivian. Beckett/Beckett. The classic study of a modern genius. New York: Oxford University Press, 1977.

PHILIPS, James. “Beckett's Boredom”. In: DALLE PEZZE, Barbara, e SALZANI, Carlo (org.). Essays on Boredom and Modernity. Nova York: Rodopi, 2009. pp. 109-126.

POTHAST, Ulrich. Die eigentlich metaphysische Tätigkeit: über Schopenhauers Ästhetik und ibre Anwendung durch Samuel Beckett. Frankfurt: Suhrkamp, 1989.

SALLENAVE, Danièle. "Em torno do 'monólogo interior': leitura de uma teoria”. In: Masculino, Feminino, Neutro. Ensaios de semiótica narrativa. Trad. T. Franco Carvalhal et al. Porto Alegre: Editora Globo, 1976, pp. 105-126.

SOKOLOWSKI, Robert. Introdução à fenomenologia. Trad. A. de Oliveira Moraes. São Paulo: Ed. Loyola, 2004.

STALLYBRASS, Peter. O casaco de Marx. Roupas, memória, dor. Trad. T. Tadeu. Belo Horizonte: Autêntica, 2008.

SVENDSEN, Lars. Filosofia do tédio. Trad. M. L. X. de A. Borges. Rio de Janeiro: Zahar, 2006.

TOOHEY, Peter. Boredom. A lively history. Londres: Yale University Press, 2011.

WALSER, Robert. Absolutamente nada e outras histórias. Trad. S. Tellaroli. São Paulo: Editora 34, 2014. 
